\title{
Network Interference Negatively Predicts Relationship Quality and Mental Health in Dating Couples
}

Blakely Murphy, BA Adelphi University, Garden City, New York, United States

(iD https://orcid.org/0000-0002-7293-9290

Katherine Fiori, $\mathrm{PhD}$

Adelphi University, Garden City, New York, United States

(iD https://orcid.org/0000-0003-3386-5898

James Stein, $\mathrm{PhD}$

Dixie State University, St. George, Utah, United States

(iD) https://orcid.org/0000-0002-2763-5036

Contact: blakelymurphy@mail.adelphi.edu

\section{Abstract}

Although research shows that perceived social network approval of one's romantic relationship is linked to higher levels of relationship quality and stability, whether an individual's opinion of their partner's network is associated with relationship quality and/or individual mental health remains underexplored. In the present study, we addressed this gap in the research by conducting an online survey of 202 participants between the ages of 18 and 29 who reported currently being in a nonmarital relationship of at least 6 months ( $81 \%$ female; $76 \%$ White). Four hierarchical linear regressions were performed to test the associations of reported interference from partner's friends and family, as well as reported tension regarding partner's friends and family, on relationship quality and depressive symptoms, controlling for a variety of background variables. Results revealed that reported interference from and tension about partner's friends negatively predicted relationship quality, whereas interference from and tension about partner's family did not. In contrast, neither interference from family nor friends predicted depressive symptoms, whereas tension about relationships with both family and friends positively predicted depressive symptoms. Furthermore, trust in the romantic relationship only reduced the associations between interference from and tension about partner's friends and relationship quality. Our findings indicate the importance of considering the role of the wider social network in couples' relationships.

Keywords: conflict; emerging adulthood; romantic jealousy; social support

Date Submitted: September 27, 2019 | Date Published: June 3, 2020

\section{Recommended Citation}

Murphy, B., Fiori, K., \& Stein, J. (2020). Network interference negatively predicts relationship quality and mental health in dating couples. Journal of Social, Behavioral, and Health Sciences, 14, 138-152.

https://doi.org/10.5590/JSBHS.2020.14.1.10 
Murphy et al., 2020

\section{Introduction}

Scholars speculate that romantic relationships and the contexts in which they develop mutually influence each other (Milardo, 1982). In fact, the potentially potent effects of social network members on the stability and quality of adults' romantic relationships are well documented (Doxey \& Holman, 2002; Helms et al., 2003; Sprecher et al., 2002). However, with the exception of a few studies concerning the stability of marital relationships (e.g., Fiori et al., 2018), the reverse remains underexplored. That is, how is an individuals' opinion of their partner's network associated with relationship quality and mental health? This question is particularly salient for emerging adults who are faced with the dual developmental tasks of establishing their independence by separating from family units, while at the same time forming meaningful relationships with friends and romantic partners. As such, emerging adult couples may be especially likely to report that each other's families and friends are interfering in their relationship. The purpose of the present study is to examine whether emerging adults' (ages 18-29) reports of feeling that their partners' friends and/or family interfere in their relationships are associated with relationship quality and depressive symptoms.

\section{Balancing Relationships With Friends and Family: The Primary Developmental Task of Emerging Adulthood}

Emerging adulthood is conceptualized as a period of prolonged exploration from the late teens through the 20s (ages 18-29) in which individuals try to find a good fit between self and significant others (Arnett, 2000; Collins \& Van Dulmen, 2006; Roisman et al., 2004). Scholars also posit that an individual's relationships with parents, friends, and romantic partners become further intertwined during this stage (Collins \& Van Dulmen, 2006) and serve distinct functions for the individual that enable them to achieve the developmental tasks necessary to progress into adulthood (McNamara et al., 2009). Examining the associations of perceived interconnectedness (or lack thereof) between these relationships may elucidate whether or not such interconnections may foster adaptive interpersonal functioning. We turn now to research demonstrating the importance of approval from an individual's social network for the success of that individual's romantic relationship.

\section{The Social Network Effect}

The social network effect (Felmlee, 2001) is a phenomenon that has emerged from research demonstrating the powerful role that friends and family members can play in the functioning of romantic relationships. Specifically, the social network effect refers to the idea that network approval for one's relationship boosts positive relationship outcomes, whereas disapproval can lead to relationship termination. Research indicates that ongoing positive support of the relationship from one's own and one's partner's social networks is linked to feelings of love and commitment (Doxey \& Holman, 2002), relationship satisfaction (Larson \& Holman, 1994), and relationship stability (Surra, 1990). Similarly, Parks (2007) argued that network support is associated with love, commitment, and other positive relationship phenomena. Even perceived approval from network members appears to provide relationship benefits for college-aged students (Sprecher \& Felmlee, 2000). In fact, Sinclair et al. (2015) suggest that perceived network approval is even more predictive than actual network member approval among college students.

Relatedly, disapproval of romantic relationships from individuals' family and friends has been linked to declines in relationship quality (Sinclair et al., 2015). Network members can express their disapproval directly - for example, through direct statements validating a couple member's dissatisfaction - or indirectlyfor example, through the failure to reduce feelings of tension or distress regarding their relationship (Julien et al., 1994). Julien and colleagues found that wives who were unhappy in their marriages and who discussed their dissatisfaction with similarly dissatisfied network members maintained more elevated levels of stress and relational distance from their husbands than those wives who did not discuss their relationships with 
dissatisfied friends. The authors speculated that the unadjusted confidants in distressed marriages validated the wives' dissatisfaction and were therefore unable to reduce their distress. The authors proposed the interference model to explain these findings, which suggests that relationships with certain network members (e.g., confidants) can catalyze feelings of relationship dissatisfaction by offering negative views about the partner or convincing an individual to utilize solutions that may be detrimental to the relationship.

\section{Opinions of Partner's Network Members and Relationship Quality/Stability}

As outlined above, research has addressed how approval or disapproval from members in one's social network impacts romantic relationship functioning. However, whether and how an individual's opinion of their partner's network is associated with relationship quality, particularly among young unmarried adults, is less understood. Some recent work does link these opinions to relationship stability. For example, Fiori and colleagues (2018) found that husbands' disapproval of wives' friends predicted divorce across 16 years in a sample of young adults, controlling for a variety of factors such as marital quality. In a similar vein, Sprecher and Felmlee (2000) found that a couple member's liking for individuals in their partner's social network was linked to breakup potential. However, it is unclear whether individuals' opinions of their partners' networks is also associated with relationship quality, which the present study will address.

\section{Opinions of Partner's Network Members and Mental Health}

The few studies that have examined individuals' opinions of partners' network members have linked these opinions to relationship quality and duration or stability, but not to mental health. Given that social support has been consistently linked to mental health in the literature (e.g., Hamid et al., 2014; Hengl, 1997; Russell \& Cutrona, 1991; Sarason et al., 1990), such an examination seems warranted. Although there is almost no research on the links between opinions of partners' network members and depressive symptoms, research on jealousy may shed some light on these links. For example, Mathes et al. (1985) found that fearing the loss of a romantic partner to a romantic rival, also known as romantic jealousy, may result in depressive symptoms, as well as decreased self-esteem, feelings of loneliness, and increased anxiety and anger. The jealousy stemming from the potential loss of a partner to a romantic rival appears to trigger feelings of rejection and a subsequent decrease in self-esteem and depressive symptoms. More recently, Whisman (2015) found that discovering a partner's affair was linked to subsequent major depressive episodes. Considering the previously documented potential to hinder both individual and relationship health, it is clear that an individual's opinions of their partner's social network merits further study.

\section{Potential Mechanisms Linking Opinions of Partner's Network and Relationship Stability}

Fiori and colleagues (2018) outlined potential mechanisms that may account for the link between individuals' opinions about their partner's network and relationship stability. For example, they suggest that in couples in which one partner does not approve of the partner's friends, the disapproval may actually be stemming from the fact that the partner's friends do not like the individual. Thus, it may actually be the social network effect that is driving the association between disapproval and stability. Alternatively, it could be that dislike for a partner's friends may leave an individual to wonder how he or she could be in a romantic relationship with someone with such friends, consequently negatively impacting perceptions of their partner.

The present study focuses specifically on trust as another possible mechanism linking individual's opinion of their partner's network to relationship quality. Trust has been well documented in the literature as an important component of successful romantic relationships (Barelds \& Barelds-Dijkstra, 2007). For example, Couch and Jones (1997) found that relational trust was strongly related to relationship quality and commitment in a sample of college students. This finding was supported by literature indicating that high 
levels of trust in a relationship enhance relationship quality by helping the individual perceive their partner as dependable, and be certain that he or she will behave in a pro-relationship manner in the future (Campbell \& Stanton, 2019). Relatedly, Barelds and Barelds-Dijkstra (2007) found that individuals who reported low levels of trust in their partner and experienced anxious jealousy in the presence of romantic alternatives reported significantly lower relationship quality. In the present study, we suspect that trust may be a particularly important mechanism for explaining the association between disapproval of partner's friends and relationship quality, given that friendships-particularly those with the opposite sex-may instigate jealousy and threaten trust between partners.

In addition to assessing trust as a factor linking network interference and relationship satisfaction, we also examined its potential role in explaining the relationship between network interference and depressive symptoms. As mentioned above, social support and relationship quality are undoubtedly tied to mental health, specifically depressive symptoms (e.g., Hamid et al., 2014; Hengl, 1997; Mathes et al., 1985; Russell \& Cutrona, 1991; Sarason et al., 1990; Whisman, 2015). Given that romantic alternatives within a couple's social network may threaten trust within the relationship and elicit jealous feelings, thereby decreasing the quality of the romantic relationship (Mathes et al., 1985; Whisman, 2015), depressive symptoms for one or both members of the couple may also result.

\section{The Present Study}

Despite the noted benefits of network approval and social support for relationship quality and mental health (Hamid et al., 2014; Hengl, 1997; Russell \& Cutrona, 1991; Sarason et al., 1990), there remains an inadequate understanding of how individuals' opinions about partners' social network members is associated with both relationship functioning and individual mental health. The purpose of the present study was to investigate whether individuals' opinions about their partners' social network members (specifically, friends and family) could predict relationship quality and depressive symptoms in young unmarried adults in dating relationships, and whether trust might partially explain these associations.

Based on the limited previous research outlined above, as well as on the interference model (Julien et al., 1994), we hypothesized that reporting interference from and tension about partners' friends and family would be negatively associated with relationship quality and positively associated with depressive symptoms. Furthermore, we expected trust to reduce the strength of associations between friend (but not family) interference/tension and both relationship quality and depressive symptoms. Exploring the role of an individual's opinion about their partner's network is necessary to formulate a more complete conceptual model of the dynamic relationship between couples and members of their social networks.

\section{Method}

\section{Participants}

Individuals eligible to complete the online survey were between the ages of 18 and 29 and in dating relationships of 6 months or longer. The participants were recruited via solicitation flyers posted at two universities (one in the northeast, the other in the southwest), social media posts, and a psychology subject pool (at the university in the northeast). The final sample $(N=202)$ were primarily female $(81.2 \%, n=164)$ and students $(79.7 \%, n=161)$, with a mean age of 21.32 years $(S D=2.82) ; 14.9 \%$ of the sample $(n=30)$ were exactly 18 years old. The majority of our participants reported at least some college education (83.7\%). Specifically, only two participants had some high school, with no diploma. Of the 202 participants, most (87.6\%) were non-Hispanic/Latino. Most were also Caucasian (75.7\%), with the rest of the sample identifying 
as either Asian (11.9\%), African American (5.9\%), American Indian (1.5\%), or "other" (5\%). The average relationship length was 2.27 years $(S D=1.87)$, and most of these relationships were not long distance $(76.7 \%)$. Our sample included nine same-sex relationships (4.5\%).

\section{Measures}

\section{Friend and family interference and tension}

Four questions taken from an existing study (Veroff et al., 2007: Early Years of Marriage Project) were included to assess individuals' perceptions of interference from and tension about their partner's family and friends. The first question assessed interference: "Have you ever felt that things your partner did with his/her friends/family interfered with your romantic life?” Participants were asked to respond using the following scale: o (never), 1 (rarely), 2 (sometimes), 3 (often), and 4 (everyday). Similarly, the second item assessed tension and asked participants to respond to the question, "In the past few months, how frequently have you and your partner had tension or differences about relationships with your partner's friends/family?" on the following scale: o (never), 1 (once or twice), 2 (sometimes), 3 (often), and 4 (all of the time). Because of very few scores in the "often" and "every day" categories for interference, as well as in the "often" and "all the time" categories for tension, for both scales we collapsed the scores from 0-4 to 0-2. Thus, "2" represents individuals who responded either sometimes, often, or everyday (for interference), and sometimes, often, or all the time (for tension).

\section{Relationship quality}

Romantic relationship quality was assessed using a shortened Couple's Satisfaction Index (Funk \& Rogge, 2007). This scale consists of 16 items from the original 32-item scale and is designed to measure one's satisfaction in a relationship. First, participants were asked, "Please indicate the degree of happiness, all things considered, of your relationship" on a scale from 1 (extremely unhappy) to 7 (perfect). Then, participants were asked to respond to a series of questions, such as, "How rewarding is your relationship with your partner?" on a scale from 1 (not at all) to 6 (completely). Final scores ranged from o to 81, with higher scores indicating higher levels of relationship satisfaction. Scores falling below 51.5 are thought to suggest notable relationship dissatisfaction. The shortened Couple's Satisfaction Index has been found to have strong convergent and construct validity (Funk \& Rogge), and demonstrated excellent internal consistency in the present study (Cronbach's $\alpha=0.946)$.

\section{Depressive symptoms}

To assess depressive symptoms, participants completed the Center for Epidemiologic Studies-Depression Scale (Radloff, 1977). This 20-item self-report scale was designed to measure depressive symptomatology in the general population. Participants were asked to rate a series of statements (e.g., "I felt that I could not shake off the blues even with the help of my family and friends"; "I had trouble keeping my mind on what I was doing") using a 4-point scale ranging from o (rarely or none of the time [<1 day]) to 3 (most or all of the time [5-7 days]). Items were summed to create a total score ranging from 0 to 60 , with higher scores indicating higher levels of depressive symptoms. Cronbach's alpha for the Center for Epidemiologic StudiesDepression Scale in the present study was 0.914, indicating excellent internal consistency.

\section{Open-ended questions}

Responses to open-ended items were used to better understand quantitative findings. Specifically, three openended questions were asked: (a) "If you feel there are people in your social network who interfere in your relationship, use the space below to describe how the interference of these individuals affects your relationship"; (b) "If you feel there are people in your partner's social network who interfere in your relationship, use the space below to describe how the interference of these individuals affects your 
relationship"; and (c) "Using the space below, please describe the biggest source of stress in your shared social circle with your partner.”

\section{Results}

\section{Descriptive Statistics}

Correlations among all study variables are shown in Table 1. Notably, relationship quality was significantly negatively correlated with friend interference $(r=-0.21, p<.01)$, friend tension $(r=-0.29, p<.001)$, and family tension $(r=-0.18, p<.01)$. On the other hand, depressive symptoms were positively associated with friend tension $(r=0.20, p<.01)$ and family tension $(r=0.19, p<.01)$. In addition, a paired samples $t$ test showed that mean levels of interference were significantly higher when reported about friends $(M=0.91, S D$ $=0.76)$ compared to family $(M=0.56, S D=0.76), t(201)=5.08, p<.001$. Similarly, mean levels of tension were significantly higher when reported about friends $(M=0.65, S D=0.68)$ than when reported about family $(M=0.52, S D=0.73), t(201)=1.96, p<.05$.

\section{Primary Analyses}

We ran a series of hierarchical linear regressions predicting relationship quality from friend and family interference and tension. Specifically, we conducted four hierarchical linear regressions, two predicting relationship quality, and two predicting depressive symptoms. For each regression we included two to three steps. In Step 1, the following covariates were entered: age, gender, ethnicity, race, education, income, relationship length, and whether or not the relationship was long distance. In Step 2, the family and friend variables (either interference or tension) were entered. Finally, in Step 3, trust was entered to examine whether it would decrease the strength of the relationships between the interference and tension variables and the outcome variables (only when an association was established in Step 2). 
Table 1. Correlations Among All Study Variables

\begin{tabular}{|c|c|c|c|c|c|c|c|c|c|c|c|c|c|c|}
\hline Variable & $\mathbf{1}$ & 2 & 3 & 4 & 5 & 6 & 7 & 8 & 9 & 10 & 11 & 12 & 13 & 14 \\
\hline Female & - & & & & & & & & & & & & & \\
\hline Ethnicity & 0.09 & - & & & & & & & & & & & & \\
\hline Race & 0.00 & $\begin{array}{c}- \\
0.34^{* * * *}\end{array}$ & - & & & & & & & & & & & \\
\hline Education & $0.17^{* *}$ & 0.08 & 0.03 & - & & & & & & & & & & \\
\hline Income & 0.00 & 0.05 & -0.06 & 0.04 & - & & & & & & & & & \\
\hline Long distance & -0.06 & -0.10 & -0.03 & $0.19^{* * *}$ & 0.05 & - & & & & & & & & \\
\hline $\begin{array}{l}\text { Relationship } \\
\text { length }\end{array}$ & 0.03 & -0.13 & 0.02 & $0.29^{* * * *}$ & -0.01 & 0.06 & - & & & & & & & \\
\hline Age & $0.14^{*}$ & 0.10 & 0.01 & $0.78^{* * * *}$ & 0.02 & $0.18^{* *}$ & $0.19^{* *}$ & - & & & & & & \\
\hline $\begin{array}{l}\text { Friend } \\
\text { interference }\end{array}$ & -0.09 & 0.05 & -0.05 & 0.01 & -0.11 & 0.04 & 0.09 & -0.08 & - & & & & & \\
\hline $\begin{array}{l}\text { Family } \\
\text { interference }\end{array}$ & $-0.18^{* *}$ & 0.12 & 0.10 & $0.18^{* *}$ & 0.04 & 0.01 & $0.16^{*}$ & $0.18^{* *}$ & $0.21^{* *}$ & - & & & & \\
\hline Friend tension & -0.13 & -0.10 & -0.02 & $-0.17^{* *}$ & -0.04 & 0.03 & 0.00 & $-0.19^{* * *}$ & $0.47^{* * * *}$ & 0.12 & - & & & \\
\hline Family tension & $-0.28^{* *}$ & 0.02 & -0.04 & 0.06 & 0.05 & 0.04 & $0.26^{* * * *}$ & 0.06 & 0.12 & $0.60^{* * * *}$ & $0.16^{*}$ & - & & \\
\hline $\begin{array}{l}\text { Depressive } \\
\text { symptoms }\end{array}$ & -0.11 & 0.06 & -0.08 & $-0.14^{*}$ & -0.05 & $-0.16^{*}$ & -0.05 & $-0.20^{* * *}$ & 0.13 & 0.93 & $0.20^{* *}$ & $0.19^{* *}$ & - & \\
\hline $\begin{array}{l}\text { Relationship } \\
\text { satisfaction }\end{array}$ & $0.25^{* * *}$ & -0.01 & -0.03 & -0.07 & -0.04 & -0.09 & 0.01 & 0.02 & $-0.21^{* *}$ & -0.13 & $-0.29^{* * *}$ & $-0.18^{* *}$ & $\begin{array}{c}- \\
0.34^{* * *}\end{array}$ & - \\
\hline Trust & $0.21^{* *}$ & -0.13 & -0.01 & -0.08 & 0.10 & -0.07 & -0.05 & 0.07 & 0.09 & $-0.29^{* * * *}$ & -0.12 & $-0.32^{* * *}$ & $-0.16^{* *}$ & $-0.46^{* * *}$ \\
\hline
\end{tabular}




\section{Relationship quality and friend/family interference}

As can be seen in Table 2, showing Steps 2 and 3 of the first hierarchical regression, friend interference $(\beta=$ $-0.18, p=0.02$ ) was significantly negatively associated with relationship quality, whereas family interference was not significantly associated with relationship quality $(\beta=-0.05, p=0.53)$. In Step 3 , trust was found to be very strongly and positively associated with relationship quality $(\beta=0.75, p=0.00)$, and reduced the association of friend interference to nonsignificance $(\beta=0.03, p=0.55)$.

Table 2. Hierarchical Linear Regression Predicting Relationship Satisfaction From Reported Interference From Partner's Family, Interference From Partner's Friends, and Trust

\begin{tabular}{lcccccc}
\hline \multirow{2}{*}{ Variable } & \multicolumn{2}{c}{ Without trust in the model } & \multicolumn{2}{c}{ With trust in the model } \\
\cline { 2 - 7 } & $\boldsymbol{B}$ & $\boldsymbol{S E} \boldsymbol{B}$ & $\boldsymbol{\beta}$ & $\boldsymbol{B}$ & $\boldsymbol{S E} \boldsymbol{B}$ & $\boldsymbol{\beta}$ \\
\hline Age & -0.56 & 0.48 & -0.13 & -0.44 & 0.32 & -0.10 \\
Respondent gender & 7.15 & 2.30 & $0.23^{* *}$ & 3.56 & 1.55 & $0.11^{*}$ \\
Ethnicity & -1.31 & 2.92 & -0.04 & -0.32 & 1.95 & -0.01 \\
Race & -0.56 & 0.72 & -0.06 & 0.25 & 0.48 & 0.03 \\
Education & 1.30 & 0.87 & 0.17 & 0.65 & 0.58 & 0.09 \\
Income & -0.36 & 0.45 & -0.06 & 0.15 & 0.30 & 0.02 \\
Relationship length & 0.01 & 0.46 & 0.00 & -0.36 & 0.33 & -0.05 \\
Long distance & -0.46 & 0.42 & -0.08 & -0.26 & 0.28 & -0.04 \\
Friend interference & -2.85 & 1.18 & $-0.18^{*}$ & 0.49 & 0.82 & $0.03($ n.s. $)$ \\
Family interference & -0.77 & 1.23 & -0.05 & -0.29 & 0.82 & -0.02 \\
Trust & - & - & - & 0.55 & 0.04 & $0.75^{*}$ \\
\hline
\end{tabular}

Note. n.s. = not significant.

${ }^{*} p<.05 .{ }^{* *} p<.01$.

\section{Relationship quality and friend/family tension}

Next, we examined the association between relationship quality and friend/family tension (Table 3). As predicted, there was a negative association between relationship quality and friend tension $(\beta=-0.24$, $p<.001$ ); the association was reduced by levels of trust in the relationship, as evidenced by the reduction in the beta coefficient in Step $3(\beta=-0.02, p=0.69)$. In contrast, the association between relationship quality and family tension was not significant. 
Table 3. Hierarchical Linear Regression Predicting Relationship Satisfaction from Reported Tension about Partner's Family, Tension about Partner's Friends, and Trust

\begin{tabular}{|c|c|c|c|c|c|c|}
\hline \multirow[b]{2}{*}{ Variable } & \multicolumn{3}{|c|}{ Without trust in the model } & \multicolumn{3}{|c|}{ With trust in the model } \\
\hline & $\boldsymbol{B}$ & SE B & $\boldsymbol{B}$ & SE B & $\boldsymbol{B}$ & SE B \\
\hline Age & -0.51 & 0.47 & -0.12 & -0.49 & 0.32 & -0.11 \\
\hline Respondent gender & 6.56 & 2.31 & $0.21^{* *}$ & 3.50 & 1.58 & $0.11^{*}$ \\
\hline Ethnicity & -2.78 & 2.85 & -0.07 & -0.45 & 1.94 & -0.01 \\
\hline Race & -0.69 & 0.70 & -0.07 & 0.18 & 0.48 & 0.02 \\
\hline Education & 0.89 & 0.85 & 0.12 & 0.67 & 0.58 & 0.09 \\
\hline Income & -0.27 & 0.44 & -0.04 & 0.12 & 0.30 & 0.02 \\
\hline Relationship length & 0.05 & 0.49 & 0.01 & -0.33 & 0.33 & -0.05 \\
\hline Long distance & -0.44 & 0.41 & -0.08 & -0.25 & 0.28 & -0.04 \\
\hline Friend tension & -4.29 & 1.29 & $-0.24^{* * *}$ & -0.36 & 0.92 & -0.02 (n.s.) \\
\hline Family tension & -1.34 & 1.25 & -0.08 & -0.18 & 0.86 & -0.01 \\
\hline Trust & - & - & - & 0.54 & 0.04 & $0.74^{*}$ \\
\hline
\end{tabular}

Note. n.s. $=$ not significant.

${ }^{*} p<.05 .{ }^{* *} p<.01 .{ }^{* * * *} p<.001$.

\section{Depressive symptoms and friend/family interference}

Table 4 presents the regression analysis for friend/family tension predicting depressive symptoms. In contrast to our original hypothesis, neither friend $(\beta=0.08, p=0.30)$ nor family $(\beta=0.10, p=0.19)$ interference were found to be significant predictors of depressive symptoms in Step 2, so further steps examining trust were not pursued.

Table 4. Hierarchical Linear Regression Predicting Depressive Symptoms From Reported Interference From Partner's Family and Interference From Partner's Friends

\begin{tabular}{lccc}
\hline \multicolumn{1}{c}{ Variable } & $\boldsymbol{B}$ & $\boldsymbol{S E} \boldsymbol{B}$ & $\boldsymbol{\beta}$ \\
\hline Age & -0.81 & 0.42 & -0.21 \\
Respondent gender & -1.74 & 2.00 & -0.06 \\
Ethnicity & 0.36 & 2.54 & 0.01 \\
Race & -0.80 & 0.62 & -0.10 \\
Education & 0.30 & 0.76 & 0.05 \\
Income & -0.23 & 0.39 & -0.04 \\
Relationship length & -0.23 & 0.42 & -0.04 \\
Long distance & -0.71 & 0.36 & $-0.14^{*}$ \\
Friend interference & 1.07 & 1.03 & 0.08 \\
Family interference & 1.42 & 1.07 & 0.10 \\
\hline$* 2<.05$. & & &
\end{tabular}

${ }^{*} p<.05$.

\section{Depressive symptoms and friend/family tension}

The final regression examined the relationship between depressive symptoms and friend/family tension (see Table 5). As hypothesized, Step 2 indicated that friend $(\beta=0.14, p=0.05)$ and family tension $(\beta=0.18$, $p=0.02$ ) positively predicted depressive symptoms. The introduction of trust in Step 3 only reduced the association for friend tension to nonsignificance $(\beta=-0.02, p=0.83)$. 
Table 5. Hierarchical Linear Regression Predicting Depressive Symptoms From Reported Tension About Partner's Family, Tension About Partner's Friends, and Trust

\begin{tabular}{lcccccc}
\hline \multirow{2}{*}{\multicolumn{1}{c}{ Variable }} & \multicolumn{2}{c}{ Without trust in the model } & \multicolumn{3}{c}{ With trust in the model } \\
\cline { 2 - 7 } & $\boldsymbol{B}$ & $\boldsymbol{S E} \boldsymbol{B}$ & $\boldsymbol{B}$ & $\boldsymbol{S E}$ & $\boldsymbol{B}$ & $\boldsymbol{S E} \boldsymbol{B}$ \\
\hline Age & -0.80 & 0.41 & $-0.21^{*}$ & -0.81 & 0.37 & $-0.22^{*}$ \\
Respondent gender & -0.72 & 2.00 & -0.03 & 0.86 & 1.82 & 0.03 \\
Ethnicity & 1.20 & 2.47 & 0.04 & 0.01 & 2.23 & 0.00 \\
Race & -0.60 & 0.60 & -0.07 & -1.05 & 0.55 & -0.13 \\
Education & 0.54 & 0.74 & 0.08 & 0.65 & 0.66 & 0.10 \\
Income & -0.28 & 0.38 & -0.05 & -0.48 & 0.35 & -0.09 \\
Relationship length & -0.42 & 0.43 & -0.07 & -0.22 & 0.38 & -0.04 \\
Long distance & -0.75 & 0.36 & $-0.15^{*}$ & -0.84 & 0.32 & $-0.17^{* *}$ \\
Friend tension & 2.25 & 1.12 & $0.14^{*}$ & 0.23 & 1.06 & $-0.02(n . s)$. \\
Family tension & 2.61 & 1.09 & $0.18^{*}$ & 2.02 & 0.99 & $0.14^{*}$ \\
Trust & - & - & - & -0.28 & 0.04 & -0.44 \\
\hline
\end{tabular}

Note. n.s.= not significant.

${ }^{*} p<.05 .{ }^{* *} p<.01 .{ }^{* * *} p<.001$.

\section{Discussion}

Previous research has primarily examined how friends' and family members' opinions of partners (e.g., whether they approve or disapprove of the relationship) are associated with relationship quality (e.g., Sprecher \& Felmlee, 2000). Scholars have speculated that network members may act as sounding boards with the potential to drastically alter couple dynamics (Julien et al., 1994). What remains understudied is how an individuals' opinion of their partner's network is associated with relationship quality and mental health. The present study is among the first to investigate whether individuals' reports of feeling that their partners' friends and/or family interfere in their relationships are associated with relationship quality and depressive symptoms.

\section{How Much Interference and Tension Do Participants Report?}

Interestingly, mean levels of reported interference and tension from friends was low, and from family members even lower. In fact, as outlined in our Measures section, because there were so few scores in the "often" and "every day"/"all the time" categories, we collapsed the interference item categories from a o-4 scale to a $0-2$ scale. A plausible explanation for the low mean levels of interference and tension could be related to the fact that participants were only required to be in a relationship for six months or longer. Therefore, members of a couple may not have had sufficient time to blend their respective social networks and be exposed to interference from family or friends within the integrated network, at least of the kind that may rise to a level causing tension within the romantic relationship. Further, the sample consisted of primarily college students who presumably spend a majority of their time away from their family, thus accounting for the low levels of family interference and tension. On the other hand, low levels of interference from and tension about friends may have been reported because the participants met their significant others through mutual friends who are less likely to create tension between romantic partners. Future research would benefit from examining the roles of both relationship length and how partners meet to determine whether partners 
who have been together for longer report more or less interference, and whether those who are brought together by mutual friends experience more or less interference from network members.

\section{Does Network Interference/Tension Predict Relationship Quality and Depressive Symptoms?}

Our first hypothesis that interference from and tension about members in a partner's social network will be negatively associated with relationship quality and positively associated with depressive symptoms was partially supported. As predicted, friend interference and tension negatively predicted relationship quality; tension about relationships with both family and friends positively predicted depressive symptoms. Contrary to our first hypothesis, family interference was not significantly predictive of relationship quality, and neither family nor friend interference predicted depressive symptoms. Consistent with our second hypothesis, we found that the significant associations between friend interference/tension and relationship quality, as well as that between friend tension and depressive symptoms, were weakened by trust, but the significant positive association between family tension and depressive symptoms was not.

\section{Network Interference/Tension and Relationship Quality}

Interestingly, only friend (and not family) tension and interference were associated with relationship quality. The literature indicates that young and emerging adults (i.e., aged 18-29) tend to spend more time with friends and continue expanding their friend networks as a result of normative life events, such as starting college or entering the workforce (Wrzus et al., 2017). Given the significantly higher mean levels of interference and tension from partners' friends compared to family found in our data, it could be that the potentially frequent interactions between couples and their network of friends within the college context gives the friends increased opportunity to interfere in the relationship and cause tension between partners. This may be especially relevant for our sample, because the large majority (nearly 84\%) reported "some college" education. Our findings are consistent with Julien and colleagues' (1994) interference model, which suggests that relationships with certain network members (e.g., confidants, who are often friends), specifically those who offer negative views about the partner or convince the individual to utilize solutions that may not be productive to solving relationship problems, may catalyze feelings of relationship dissatisfaction.

As predicted, trust decreased the associations between friend interference/tension and relationship quality. Thus, it is likely that interference from partners' friends detracted from the quality of the relationship by threatening trust between partners. This finding supports the well-documented importance of trust in the quality and stability of romantic relationships (Barelds \& Barelds-Dijkstra, 2007; Campbell \& Stanton, 2019; Couch \& Jones, 1997) and is also supported by participants' responses to open-ended items about network interference in the present study. Specifically, participants most commonly indicated that interference from partners' friends involved the potential threat of infidelity or friends being a bad influence on the partner's behavior (e.g., encouraging excessive drinking, experimentation with drugs, infidelity, etc.). For example, one participant wrote that the partner's friends interfered in their relationship when the partner and the friend were "secretly hanging out even when they know I won't like that because of their romantic history together." Another participant indicated that "around his friends he will smoke and drink more often and allow his behaviors to get aggressive/mean..."

\section{Network Interference/Tension and Depressive Symptoms}

Interestingly, only friend and family tension were positively associated with depressive symptoms; there appeared to be no relationship between friend and family interference and depressive symptoms. To understand this finding, it is useful to consider the participants' responses to open-ended items asking about sources of stress between partners. Specifically, these responses indicated that tension between members of a 
couple over a partner's friends tended to stem from the respondents' perception of the partner's friends as potential romantic alternatives, which Mathes et al. (1985) has linked to depressive symptoms. Furthermore, whereas interference from partner's family and friends may be acknowledged or detected by the participants, its potential effects on the participants' mental health may only become evident when that interference rises to the level of tension within the relationship.

As predicted, only the association between friend tension and depressive symptoms was reduced by trust. As previously mentioned, fear of one's partner cheating with a member of their social circle, as well as friends negatively influencing their partner's behavior (e.g., encouraging excessive drinking, experimentation with drugs, infidelity, etc.), were both commonly reported as sources of stress between couple members in responses to open-ended questions. Considering the known links between trust, relationship quality, and depressive symptoms (Barelds \& Barelds-Dijkstra, 2007; Campbell \& Stanton, 2019; Couch \& Jones, 1997; Mathes et al., 1985; Whisman, 2015), relationship issues that threaten trust-such as those mentioned above regarding partners' friends-may decrease the quality of the romantic relationship and subsequently make an individual more susceptible to developing depressive symptoms. In contrast, unsolicited advice or opinions as well as demands for the partner's time were among the most frequently reported sources of interference from the partner's family members in the open-ended responses. Such issues do not necessarily lead to a lack of trust within the relationship; rather, tension about these issues may lead to more conflictual interactions with the partner that could influence the participant's reported levels of depressive symptoms.

\section{Limitations and Future Research}

The results of this study reveal the importance of considering the role of the wider social network in couples' relationships and contribute to the very small literature on this topic. However, there are certain limitations to these findings. For example, as mentioned earlier, one's opinions about their partner's social network may be distorted by the network members' opinions of them. However, in the present study, we did not collect data from the network members themselves. Thus, we are unable to determine if the participant's perceived interference is actually due to the partner's network members not liking/approving of them. Furthermore, we used self-report measures that assess only respondents' perceived interference from partner's network. Not only could the partner's family or friends not be as 'objectively' disapproving as the individual perceives, but the opinion of the partner about the network members may also be important. For example, if both members of a couple agree that a particular network member is interfering in their relationship, that interference may be less detrimental to the quality of their relationship than if one partner sees the network member as intrusive and the other partner does not. Future research should interview both partners and members from both partner's social networks to fully understand the complex dynamics between couples and their networks.

Another noteworthy limitation of this study is that only one item was used to assess each of the four constructs of interest: friend interference, friend tension, family interference, and family tension. Thus, psychometric properties, such as internal consistency, could not be assessed. Furthermore, these rather broad questions make it difficult to identify specific interference behaviors from a partner's network and the severity of the tension about such members. Relatedly, some may question whether such broad items accurately capture the construct of interference. However, the benefit of such broad questions is that they allow for subjective interpretation. Based on the open-ended data, it seems that participants interpreted interference in the way that we intended; that is, behaviors from network members that in some way hindered the productive functioning of their romantic relationship or mental health. The interpretation of 'interference' ranged from the amount of time the partner was spending with their friends (interfering with the romantic relationship because it resulted in less time to spend with the partner), to more subjective reasons (e.g., not liking that your partner goes drinking with their friends, or not liking the fact that the partner is talking about the 
romantic relationship with their family, etc.). Future research may benefit from assessing network interference with a multi-item measure that captures the multidimensional nature of this interference.

Our decision to restrict our sample to that of emerging adults could also be considered a limitation. Although we selected this age group because they may be particularly likely to experience difficulties in merging their existing social networks with those of their new romantic partner's, it is not clear whether our results would generalize to other age groups. There is some indication in the literature that this merging is challenging even for middle-aged adults in later stages of their romantic relationships (i.e., Fiori et al., 2018), but that research was focused on divorce as the outcome. Future research is needed to determine whether our findings concerning the association of perceived interference/tension with relationship quality and depressive symptoms are specific to emerging adults, or whether these associations would hold true for other age groups (e.g., those in longer term relationships; those not living in a college context) as well.

Finally, the correlational nature of this study limits our ability to determine the direction of the association between reports of interference from one's partner's social network and relationship quality. In other words, it is possible that individuals in poorer quality relationships are reporting more interference and/or tension from partner's friends. Although either direction is plausible, the qualitative data collected in our study lends some support to our original hypothesis that interference from and tension about members in one's partner's network negatively predicts romantic relationship quality. It is critical for future researchers to follow couples over time to better understand the directionality of effects, and experimental studies (e.g., using vignettes) could be used to assess causal directions between interference and relationship dynamics.

\section{Conclusions and Practical Implications}

Shared networks have the ability to increase available social resources for both members of a couple (Acock \& Demo, 1994). However, the present study investigated one of the inevitable challenges that arise when integrating two separate social networks-that is, perceived interference from and tension about partner's friends and family. Our findings highlight the implications of such interference and tension for relationship quality and mental health. From a practical standpoint, relationship therapists may consider helping patients acknowledge the impact of their networks on the couple as a unit and as individuals. It would be useful for couples experiencing conflicts with members of their partner's network with whom the partner cannot end their relationship (e.g. parents, siblings, etc.) to reframe their opinions on what they perceive as problematic interference. For instance, individuals who perceive frequent unsolicited opinions from their partner's parents as interference may benefit by re-evaluating such opinions as advice for how to maintain a healthy and satisfying romantic relationship. Collectively, our findings reveal information essential to sustaining healthy relationships with one's partner and their network members, as well as the impact of such relationships on mental health.

\section{References}

Acock, A. C., \& Demo, D. H. (1994). Family diversity and well-being. Sage.

Arnett, J. J. (2000). Emerging adulthood: A theory of development from the late teens through the twenties. American Psychologist, 55(5), 469-480. https://doi.org/10.1037/0003-066X.55.5.469

Barelds, D. P., \& Barelds-Disjkstra, P. B. (2007). Relations between different types of jealousy and self and partner perceptions of relationship quality. Clinical Psychology and Psychotherapy, 14, 176-188. https://doi.org/10.1002/cpp.532

Campbell, L., \& Stanton, S. (2019). Adult attachment and trust in romantic relationships. Current Opinion in Psychology, 25, 148-151. https://doi.org/10.1016/j.cosyc.2018.08.004 
Collins, W., \& Van Dulmen, M. (2006). Friendships and romance in emerging adulthood: Assessing distinctiveness in close relationships. In J. J. Arnett \& J. L. Tanner (Eds.), Emerging adults in america: Coming of age in the 21st century (pp. 219-234). American Psychological Association.

Couch, L. L., \& Jones, W. H. (1997). Measuring levels of trust. Journal of Research in Personality, 31, 319-336.

Doxey, C., \& Holman, T. B. (2002). Social contexts influencing marital quality. In T. B. Holman (Ed.), Premarital prediction of marital quality or breakup (pp. 119-139). Springer. https://doi.org/10.1007/0-306-47186-8 6

Felmlee, D. H. (2001). No couple is an island: A social network perspective on dyadic stability. Social Forces, 79(4), 1259-1287. https://doi.org/10.1353/sof.2001.0039

Fiori, K. L., Rauer, A. J., Birditt, K. S., Marini, C. M., Jager, J., Brown, E., \& Orbuch, T. L. (2018). "I love you, not your friends": Links between partners' early disapproval of friends and divorce across 16 years. Journal of Social and Personal Relationships, 35(9), 1230-1250.

Funk, J. L. \& Rogge, R. D. (2007). Testing the ruler with item response theory: Increasing precision of measurement for relationship satisfaction with the Couples Satisfaction Index. Journal of Family Psychology, 21, 572-583.

Helms, H. M., Crouter, A. C., \& McHale, S. M. (2003). Marital quality and spouses' marriage work with close friends and each other. Journal of Marriage and Family, 65, 963-977. $\underline{\text { https://doi.org/10. }}$ 1111/j.1741-3737.2003.00963.x

Hengl, C. (1997). Role of perceived social support on depression in Chinese adolescents: A prospective study examining the buffering model. Journal of Applied Social Psychology, 27, 800-820.

Julien, D., Markman, H. J., Leveille, S., Chartrand, E., \& Begin, J. (1994). Networks' support and interference with regard to marriage: Disclosures of marital problems to confidants. Journal of Family Psychology, 8(1), 16-31.

Larson, J. H., \& Holman, T. B. (1994). Premarital predictors of marital quality and stability. Family Relations, 43, 228-237. https://doi.org/10.2307/585327

Mathes, E. W., Adams, H. E., \& Davies, E. M. (1985). Jealousy: Loss of relationship rewards, loss of selfesteem, depression, anxiety, and anger. Journal of Personality and Social Psychology, 48(6), 15521561.

McNamara, C., Madsen, S., Nelson, L., Carroll, J., \& Badger, S. (2009). Friendship and romantic relationship qualities in emerging adulthood: Differential associations with identity development and achieved adulthood criteria. Journal of Adult Development, 16(4), 209-222 .

Milardo, R. M. (1982). Friendship networks in developing relationships: Converging and diverging social environments. Social Psychology Quarterly, 45, 162-172.

Parks, M. (2007). Personal relationships and personal networks. New York, NY.

Radloff, L. S. (1977). The CES-D Scale: A self-report depression scale for research in the general population. Applied Psychological Measurement, 1(3), 385-401. https://doi.org/10.1177/014662167700100306

Rogge, R. D., Fincham, F., Crasta, D., \& Maniaci, M. (2017). Positive and negative evaluation of relationships: Development and validation of the positive-negative relationship quality (PN-RQ) scale. Psychological Assessment, 29(8), 1028-1043.

Roisman, G., Masten, A., Coatsworth, J., \& Tellegen, A. (2004). Salient and emerging developmental tasks in the transition to adulthood. Child Development, 75(1), 123-133. 
Roohafza, H. R., Afshar, H., Keshteli, A. H., Mohammadi, N., Feizi, A., Taslimi, M., \& Adibi, P. (2014). What's the role of perceived social support and coping styles in depression and anxiety? Journal of Research in Medical Sciences, 19(10), 944-949.

Russell, D. W., \& Cutrona, C. E. (1991). Social support, stress, and depressive symptoms among the elderly: Test of a process model. Psychology and Aging, 6(2), 190-201. https://doi.org/10.1037/08827974.6.2.190

Sarason, B. R., Sarason, I. G., \& Pierce, G. R. (1990). Social support: An interactional view. John Wiley and Sons.

Sinclair, H. C., Felmlee, D., Sprecher, S., \& Wright, B. L. (2015). Don't tell me who I can't love: A multimethod investigation of social network and reactance effects on romantic relationships. Social Psychology Quarterly, 78(1), 77-99. https://doi.org/10.1177/019027251456253

Sprecher, S., \& Felmlee, D. (2000). Romantic partners' perceptions of social network attributes with the passage of time and relationship transitions. Personal Relationships, 7, 325-340.

Sprecher, S., Felmlee, D., Orbuch, T. L., \& Willetts, M. C. (2002). Social networks and change in personal relationships. In A. Vangelisti, H. Reis, \& M. Fitzpatrick (Eds.), Stability and change in relationships (pp. 257-284). Cambridge, United Kingdom: Cambridge University Press.

Surra, C. A. (1990). Research and theory on mate selection and premarital relationships in the 1980s. Journal of Marriage and the Family, 52, 844-865. https://doi.org/10.2307/353306

Veroff, J., Douvan, E., Hatchett, S., \& Orbuch, T. (2007, October 3). Early Years of Marriage (EYM) Project, Years 1-4, 1986-1989. Inter-University Consortium for Political and Social Research [Distributor], https://doi.org/10.3886/ICPSR04557.v1

Whisman, M. (2015). Discovery of a partner affair and major depressive episode in a probability sample of married or cohabitating adults. Family Process, 55(4), 713-723. https://doi.org/10.1111/famp.12185

Wrzus, C., Zimmermann, J., Mund, M., \& Neyer, F. J. (2017). Friendships in young and middle adulthood: Normative patterns and personality differences. In M. Hojjat \& A. Moyer (Eds.), The psychology of friendship (pp. 21-38). Oxford University Press.

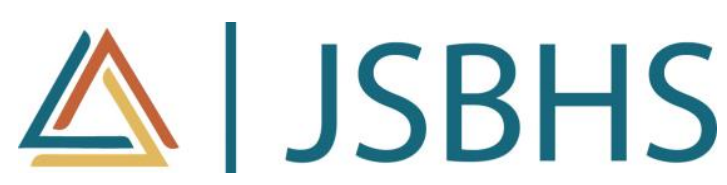

The Journal of Social, Behavioral, and Health Sciences (JSBHS), co-sponsored by the College of Health Sciences and the College of Social and Behavioral Sciences at Walden University, is a peer-reviewed, online, interdisciplinary journal focusing on theoretically-based research that addresses contemporary national and international issues. JSBHS articles include peer-reviewed research reports, brief resports, comprehensive literature reviews, books reviews, and student research. 